\title{
The Influence of Early Malnutrition on Subsequent Behavioral Development III. Learning Disabilities as a Sequel to Malnutrition
}

\author{
JANINA R. GALLER, ${ }^{(20)}$ FRANK RAMSEY, AND GIORGIO SOLIMANO, \\ Department of Child Psychiatry, Boston University School of Medicine, Boston, Massachusetts USA [J.R.G.]; \\ National Nutrition Centre, Barbados, West Indies [F.R.]; and Institute of Human Nutrition and Center for \\ Population and Family Health, Columbia University, New York, New York, USA [G.S.].
}

\begin{abstract}
Summary
The academic performance of 129 Barbadian children ( 77 boys and 52 girls), who were 5-11-yr-old and suffered moderate to severe protein-energy malnutrition in the first year of life, was compared with the performance of matched comparisons, children who had no history of malnutrition. Children with a history of malnutrition were found to have lower performance on eight out of nine academic subject areas, namely, language arts, mathematics, general science, social science, reading, health, religion, and arts/crafts. Socioeconomic factors in the backgrounds of the children were also examined. A model is presented clarifying the interrelationships of malnutrition, socioeconomic status and school performance. Reduced school performance in the previously malnourished children can be largely accounted for by deficits in classroom behavior, and, to a lesser extent by a reduction in I.Q. Current socioeconomic status is not directly involved in altering academic performance whereas the early history of malnutrition and its accompanying conditions at the time of the illness are leading contributors to altered behavioral outcome and school performance.
\end{abstract}

\section{Abbreviations}

PEM, protein energy malnutrition

WISC, Wechsler Intelligence Scale for Children

This report is one of a series of studies comparing 129 boys and girls who were 5-11-yr-old and had moderate to severe PEM in the first year of life, with 129 matched control children who had no history of malnutrition. The objective of these studies was to provide a comprehensive description of the long-term consequences of malnutrition occurring early in life in a welldocumented population of school-aged children in Barbados. In the earlier papers we described the presence of deficits in I.Q. and classroom behavior in the children with previous malnutrition $(4,5)$. The purpose of this paper is to examine the consequences of early, severe malnutrition in the child's academic performance, as measured by grades achieved in school. We report a reduction in the grades of children with histories of malnutrition and correlate academic performance to I.Q., classroom behavior, and socioeconomic background. This allows us to develop a model of the behavioral effects of early malnutrition as seen when the child is between 5-11 yr of age.

\section{MATERIALS AND METHODS}

Site of study. The current study was conducted at the National Nutrition Centre, Bridgetown, Barbados. This Centre was established in 1967 to follow the development of all children in
Barbados diagnosed as being malnourished. Since its inception, the Nutrition Centre at the Queen Elizabeth Hospital has treated and provided follow-up care for approximately 2100 children. Extensive records of diagnosis, treatment, and follow-up to 12 yr of age are available for each child. The availability of these records has allowed us to select a well-documented population of children who had marasmus during the first year of life. Several features of this island population were especially favorable to our investigation. First, health care delivery is good. Almost all children are born in the Queen Elizabeth Hospital or allied facilities, and well-documented records of obstetric care are available in almost all cases. Furthermore, children are routinely followed by local clinics and these records were made available for the current study. Second, Barbados has the highest literacy rate in the West Indies (98\%), with nearly all children attending school. Third, the population is homogeneous and stable, $95 \%$ being blacks of West African origin. Fourth, the country is small and readily accessible so that no group is overlooked. This combination of factors made Barbados an ideal setting for the current study.

Study Population, exposed series $(n=129)$. Index cases selected for the current study included all children who had been hospitalized at the Queen Elizabeth Hospital from 1967-1972 with malnutrition and who had been diagnosed by one of us (F.R.) with grade II-III PEM according to the Gomez Scale (7) during the first year of life. No cases of edema were included, and all the children had marasmus. The mean age at admission was $6.5 \pm 3 \mathrm{mo}$ and the mean length of hospitalization was 37 $\pm 5 \mathrm{~d}$. The children received medical care through the National Nutrition Centre for up to $11 \mathrm{yr}$ including home visits by public health nurses, and families were provided with nutrition counselling and subsidized milk during this time period. Further episodes of malnutrition in this population are rare, and any children with evidence of a second bout of such illness were excluded from the index group. The following criteria were applied for the selection of index children.

1) In order to exclude those children exposed to significant intrauterine growth retardation, the birth weight of the infant had to be $\geq 5 \mathrm{lb}$.

2) Cases with prenatal or perinatal complications, as measured by standard criteria including the Apgar score, were eliminated to exclude other causes of impaired development.

3) Children with a history of convulsions, head injury, or loss of consciousness were also excluded.

This information was obtained by reviewing obstetric records of all mothers and perinatal records of all children followed by the National Nutrition Centre. Of the 140 children who met these criteria 11 were eliminated due to the following reasons: seven cases were lost to follow-up and in four cases parents 
refused to grant permission for their child to participate. The final group consisted of 77 boys and 52 girls.

Study population, non-exposed series $(n=129)$. The nonexposed (comparison) series met the same criteria applied in the selection of the index series except that these children had no history of PEM. To qualify for inclusion, the comparison child was required to have had at least three recorded medical visits in the first year of life, reporting normal growth and development, and two similar reports each year before school admission which is part of the health care service for all Barbadian preschool children. During the school years, growth was measured annually and evidence of normal development was also recorded for the comparison group.

For our study, the comparison children were selected from the same classrooms and schools as the index children whenever possible and matched to the index children by age, sex, and right or left hand dominance. In the few cases where this was not possible because of inadequate health records of children in the class, a child from a neighborhood health care centre was selected. This procedure of selecting schoolmates or neighborhood children was used to control for socioeconomic and other environmental factors as much as possible.

Data collected: academic performance. Grades in school were collected from school records for both semesters of the 1977 academic school year by a school official who was unaware of the nutritional history of the child. Each academic subject was evaluated on a six point scale ranging from 1 (very poor) to 6 (excellent performance). The following subject areas were evaluated: reading (including comprehension), language arts (including oral recitation, composition, grammar, English, discussion, spelling), writing, mathematics, general science, social science (including social education and social studies), religion, health, and practical arts/crafts (including handiwork and needlework).

Classroom behavior, I.Q., and socioeconomic status. The results of the I.Q. tests and classroom behaviors and their relationships to current socioeconomic conditions have been described in detail in earlier papers of this series $(4,5)$. Briefly, data on classroom behaviors were gathered from questionnaires administered to teachers who had no knowledge of child's previous nutritional history. I.Q. was measured using a version of the WISC, modified for Barbadian children. Data concerning the physical and economic resources in the homes of children used in this study were collected from a 22-item interview schedule and was administered to the child's primary caretaker by a public health nurse. This questionnaire was similar to that used by Richardson (12) in Jamaica.

Data analysis. All analyses were performed using the Statistical
Package for the Social Sciences (9). The marks for both semesters were combined. A $2 \times 2$ analysis of variance (nutritional status by sex) was performed for each academic subject. Regression analyses were then performed to determine 1) the independent variance contribution of socioeconomic status and nutritional history to academic performance and 2) the proportion of variance in academic performance explained by nutritional history when the effects of I.Q. and classroom behavior were controlled.

\section{RESULTS}

Table 1 shows the mean grades in school obtained by the index and comparison children as reported in their class records. Table 2 shows the results of ANOVA applied to these data, which are based on a scale of 1 (very poor performance) to 6 (excellent performance). The scores of index children were significantly lower than those of comparison children on eight out of nine school subjects. For five of these (language arts, math, general science, social science, and religion), there were significant differences between index and comparison groups at $P<0.01$ or better, and for the remaining three subjects (reading, health, and arts/crafts), at $P<0.05$. Prior nutritional history had no effect on writing. A significant sex effect was present for three school subjects, namely, language arts, health, and religion with girls performing better than boys. There were no significant interactions between nutritional history and sex on any of the academic subjects.

Thirty-seven children ( 21 boys and 16 girls) were below the appropriate grade for age. The data were reanalyzed excluding

Table 2. Analysis of variance ( $F$ values) on marks in school by nutritional history and sex

\begin{tabular}{lcccc}
\hline Class subject & df & $\begin{array}{c}\text { Nutritional } \\
\text { history }\end{array}$ & Sex & Interaction \\
\hline Language arts & 1,208 & $35.40^{*}$ & $9.42 \dagger$ & 1.36 \\
Mathematics & 1,214 & $38.67^{*}$ & 2.79 & 1.88 \\
General science & 1,126 & $25.42^{*}$ & 1.58 & 3.08 \\
Social science & 1,127 & $12.56^{*}$ & 3.64 & 0.31 \\
Reading & 1,123 & $5.34 \ddagger$ & 1.88 & 1.76 \\
Religion & 1,95 & $9.93 \dagger$ & $6.20 \dagger$ & 0.85 \\
Health & 1,63 & $4.56 \ddagger$ & $8.91 \dagger$ & 0.04 \\
Arts/crafts & 1,90 & $4.76 \ddagger$ & 0.10 & 1.06 \\
Writing & 1,60 & 0.64 & 1.03 & 0.06 \\
\hline
\end{tabular}

$* P<0.001$.

$\dagger P<0.01$.

$\ddagger P<0.05$.

Table 1. Comparison between index and comparison children on marks in school*

\begin{tabular}{lllll}
\hline \multicolumn{1}{c}{ Class subject } & Group & Girls & Boys \\
\hline Language arts & Comparison & $4.28 \pm 1.05$ & $3.60 \pm 1.20$ & $3.87 \pm 1.18$ \\
$(n=209)$ & Index & $3.11 \pm 1.22$ & $2.81 \pm 1.10$ & $2.93 \pm 1.15$ \\
Mathematics & Comparison & $4.19 \pm 1.28$ & $3.65 \pm 1.33$ & $3.87 \pm 1.33$ \\
$(n=215)$ & Index & $2.81 \pm 1.21$ & $2.77 \pm 1.28$ & $2.79 \pm 1.24$ \\
General science & Comparison & $4.14 \pm 0.81$ & $3.60 \pm 1.12$ & $3.81 \pm 1.04$ \\
$(n=127)$ & Index & $2.85 \pm 0.95$ & $2.95 \pm 1.00$ & $2.91 \pm 0.97$ \\
Social science & Comparison & $4.10 \pm 0.91$ & $3.64 \pm 1.07$ & $3.81 \pm 1.03$ \\
$(n=128)$ & Index & $3.33 \pm 1.02$ & $3.08 \pm 1.05$ & $3.17 \pm 1.04$ \\
Reading & Comparison & $4.22 \pm 1.26$ & $3.62 \pm 1.25$ & $3.84 \pm 1.29$ \\
$(n=124)$ & Index & $3.35 \pm 1.17$ & $3.35 \pm 1.11$ & $3.35 \pm 1.12$ \\
Religion & Comparison & $4.30 \pm 1.18$ & $3.53 \pm 1.02$ & $3.84 \pm 1.14$ \\
$(n=96)$ & Index & $3.31 \pm 1.05$ & $2.98 \pm 1.20$ & $3.11 \pm 1.14$ \\
Health & Comparison & $4.28 \pm 0.77$ & $3.47 \pm 0.93$ & $3.85 \pm 0.94$ \\
$(n=64)$ & Index & $3.68 \pm 1.12$ & $2.97 \pm 1.16$ & $3.23 \pm 1.18$ \\
Arts/crafts & Comparison & $3.94 \pm 1.00$ & $4.23 \pm 1.07$ & $3.13 \pm 1.04$ \\
$(n=91)$ & Index & $3.77 \pm 0.98$ & $3.59 \pm 1.05$ & $3.65 \pm 1.02$ \\
Writing & Comparison & $3.60 \pm 0.74$ & $3.37 \pm 1.38$ & $3.45 \pm 1.20$ \\
$(n=61)$ & Index & $3.46 \pm 1.18$ & $3.08 \pm 0.97$ \\
\hline
\end{tabular}

* Mean \pm standard deviation. 
these children and their matched comparisons because they had already been identified as having some degree of school failure. The results of ANOVA for the smaller sample $(n=184)$ were similar to those obtained for the total population except that nutritional history no longer had a significant effect on reading or health. These findings suggest that deficits in reading are overrepresented among children already identified with school failure. In addition, sex effects were significant for six out of nine subjects, namely math $[\mathrm{F}(1,162)=4.6, P<0.05]$, general science $[\mathrm{F}(1,90)=5.4, P<0.05]$, social science $[\mathrm{F}(1,92)=5.2, P<$ $0.05]$, language arts $[\mathrm{F}(1,163)=11.20, P<0.001]$, health $[\mathrm{F}$ $(1,40)=14.16, P<0.001]$, and religion $[\mathrm{F}(1,70)=6.47, P<$ $0.05]$ with girls doing better than boys. There were no interactions between nutritional history and sex for the analysis of 184 children, as for the larger sample.

Correlations between academic performance, I.Q., and classroom behavior. We first examined the interrelationships between performance among the major academic subjects, namely, reading, language arts, math, general science, and social science. Pearson correlations (one-tailed) among these school subjects were strongly positive ranging from $0.54-0.83$. We have previously reported deficits in classroom behavior and I.Q. in index children who were compared with children having no history of malnutrition $(4,5)$. In this section, we also report Pearson correlations of performance in the various subject areas with different aspects of classroom behavior and I.Q. Classroom behavior was assessed using a questionnaire administered blindly to the teachers of index and comparison children. This questionnaire was factor-analyzed, resulting in seven factors, four of which were distinguished significantly between index and comparison children. The four factors characteristic of index children included behaviors associated with attention deficit disorder, emotional lability, poor physical appearance, and reduced social skills. Performance on all five major academic subjects was significantly correlated with two of these classroom behavior factors. Lower marks in the five major subjects were correlated (range, 0.56-0.63) with attention deficit disorder (lack of attention, poor memory, poor motivation, easy distractibility, and restlessness) and with poor social skills (range, $0.22-0.35$ ). In contrast, marks in school were not associated with altered physical appearance of the child or emotional lability, though both were also more frequent in index children. We then examined the relationship between academic performance and I.Q. The full scale I.Q. was significantly correlated with academic performance on the five major subjects (range, $0.37-0.57$ ). This range is similar to that reported for U.S. populations (1) but lower than that reported above for classroom behavior and academic performance.

Correlations between nutritional history, classroom behavior, and academic performance. We next examined whether malnutrition has a direct effect on school performance or whether its effects are mediated by deficits in classroom behavior or I.Q. A series of multiple correlations were performed in order to evaluate the relationship between school performance and nutritional history, in which the effects of classroom behavior and I.Q. were controlled. Table 3 shows that the correlations between performance on the nine school subjects and nutritional history are significant for eight of these, ranging between $0.20-0.41$. All the correlations between performance on the school subjects and classroom behavior are significant, ranging from $0.47-0.75$. When we controlled for classroom behavior, the correlations between performance on the school subjects and nutritional history are, in general, no longer significant ( $r$ when classroom behavior is entered first and nutritional history entered second). This implies that the relationship of nutritional history to academic performance is mediated through classroom behavior. A similar analysis of performance on school subjects and I.Q. shows significant correlations between these variables ranging from $0.36-0.55$, which are about one-half of the $r$ values for performance in school subjects and classroom behavior. When the effects of I.Q. were controlled, performance on three school subjects remained significantly correlated with nutritional history ( $r$, when I.Q. is entered first and nutritional history is entered second). These results suggest that classroom behavior and, to a lesser extent, I.Q. are responsible for the poor performance in school of previously malnourished children. It should be noted that I.Q. is significantly correlated with classroom behavior, in particular with attention deficit disorder $(r=0.48)$ and social skills $(r=0.25)$.

Relationship between socioeconomic status and academic performance. In earlier papers $(4,5)$ we reported that current socioeconomic conditions do not contribute to deficits in classroom behavior and I.Q. in previously malnourished children. In the present analyses, we confirm that current socioeconomic conditions (including physical and economic resources) do not contribute to the reduction in academic performance observed in the index group and, unlike classroom behavior and I.Q., are not responsible for mediating the consequences of early malnutrition (Table 4).

In this study, data concerned with the physical and economic resources in the homes of children were collected from a 22-item interview schedule, administered to the child's primary caretaker by a public health nurse. This interview schedule was modified from Richardson (12) for use in this population. The socioeconomic interview was factor-analyzed using a seven-factor solution, and analysis showed that three factors distinguished between index and comparison children. In the case of all three significant factors, socioeconomic conditions in families from the index group were disadvantaged. The first significant factor referred to conveniences in the home, including the presence of a refrigerator, electricity, television, and running water; the second referred to the degree of crowding in the home, including

Table 3. Multiple regression analyses of marks in school with nutritional history, classroom behavior, and full I.Q., controlling for sex ( $r$ values)

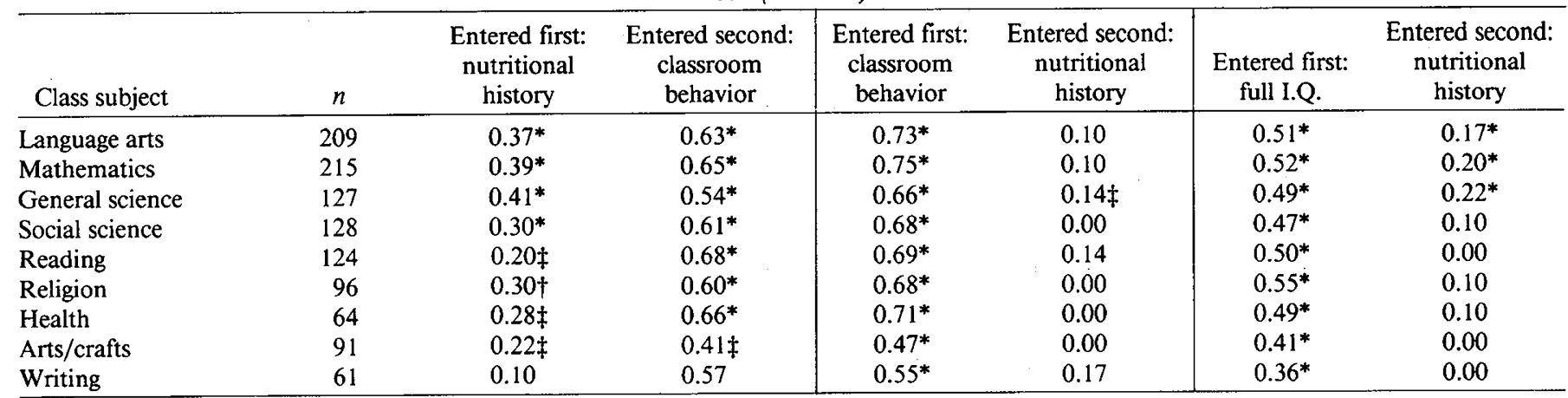

\footnotetext{
${ }^{*} P<0.001$.

$\dagger P<0.01$.

$\ddagger P<0.05$.
} 
Table 4. Multiple regression analysis of marks in school with nutritional history and socioeconomic status (SES) controlling for sex

\begin{tabular}{lccc|cc}
\hline Class subject & $n$ & $\begin{array}{c}\text { Entered first: } \\
\text { nutritional history }\end{array}$ & $\begin{array}{c}\text { Entered second: } \\
\text { SES }\end{array}$ & $\begin{array}{c}\text { Entered first: } \\
\text { SES }\end{array}$ & $\begin{array}{c}\text { Entered second: } \\
\text { nutritional history }\end{array}$ \\
\hline Language arts & 209 & $0.37^{*}$ & 0.20 & $0.24 \ddagger$ & $0.35^{*}$ \\
Mathematics & 215 & $0.39^{*}$ & 0.14 & 0.20 & $0.36^{*}$ \\
General science & 127 & $0.41^{*}$ & 0.24 & 0.22 & $0.42^{*}$ \\
Social science & 128 & $0.30^{*}$ & 0.20 & 0.14 & $0.30^{*}$ \\
Reading & 124 & $0.20 \ddagger$ & 0.14 & 0.22 & $0.37 \ddagger$ \\
Religion & 96 & $0.30 \dagger$ & 0.26 & 0.32 & 0.14 \\
Health & 64 & $0.28 \ddagger$ & 0.30 & 0.10 & $0.49 \ddagger$ \\
Arts/crafts & 91 & $0.22 \ddagger$ & 0.10 & $0.48 \ddagger$ & 0.00 \\
Writing & 61 & & & & 0.49 \\
\hline
\end{tabular}

$$
\begin{aligned}
& * P<0.001 . \\
& \dagger P<0.01 . \\
& \ddagger P<0.05 .
\end{aligned}
$$

the number of bedrooms and other rooms, and the number of beds; and the third referred to the type of work done by the father and the major sources of income to the family. We can conclude that the standard of living is presently better in the families of those children not previously malnourished.

In order to determine the relationships between academic performance and socioeconomic status, two regression equations were generated (Table 4). Because sex differences were reported earlier, sex was held constant in each of these equations. In the first set of equations, nutritional history was entered before the seven socioeconomic factors. In the second set of equations, these socioeconomic factors were entered before nutritional history. All seven socioeconomic factors-not just the three which distinguished between the series-were entered into the equation as a group to maximize the amount of variance contributed by socioeconomic conditions.

As may be seen, the nutritional history was significantly correlated with eight academic subjects ( $r$ value when nutritional history was entered first); however, nutritional history was still significantly correlated with academic performance even when the socioeconomic factors were controlled $(r$ value for when nutritional history was entered second). Socioeconomic factors were generally not correlated with performance on school subjects whether entered first or second into the regression equation. These results indicate that a previous history of PEM (or some factor associated with its occurrence) and not current socioeconomic conditions accounted for the major proportion of variance in academic performance.

\section{DISCUSSION}

In the current paper, academic performance was reduced on eight out of nine classroom subjects in children with a prior history of malnutrition when compared with age-matched control children. This index group had been reported previously by us to have impaired classroom behavior (5) and reduced intellectual quotients (4). The interrelationships between these variables are presented in Figure 1 as correlation coefficients. This figure shows moderate correlations between the full scale I.Q. scores and performance on each of five major classroom subjects (results are similar for the remaining significant subjects). Deficits in classroom behavior are also significantly correlated with reduced performance on the school subjects. As reported in Figure 1 , the $r^{2}$ values in each case are higher than those reported for the corresponding correlations between I.Q. and on the school subjects; thus classroom behavior appears to be the more important contributor to academic performance than is I.Q. This is confirmed (Table 3 ) by the persistence of significant correlations between nutritional history and academic performance even when I.Q. is controlled, whereas controlling for classroom behavior eliminates the correlation of nutritional history with academic performance. The effects of malnutrition must, therefore, operate through changes in classroom behavior.
Current socioeconomic status shows a low but significant correlation with a history of malnutrition because index families tended to be somewhat disadvantaged at the time of the study. As seen in Figure 1, no significant relationship was obtained between socioeconomic condition and I.Q. or classroom behavior. When the socioeconomic factors are controlled, early malnutrition continues to have a major association with I.Q. (4) and classroom behavior (5) and, as a result, also with academic performance (Table 4). Conversely, none of these indices is correlated with current socioeconomic status when nutritional history is controlled as a factor. Consequently, we conclude that early malnutrition results in impaired academic performance mainly through deficits in classroom behavior and, to a lesser degree, by I.Q., whereas it is not mediated by factors in the current social environment.

Other studies confirm that children with early histories of severe malnutrition perform less effectively in school than do children with no history of malnutrition $(3,8,10,13,14,16)$. These children are at risk of continued school failure and eventually are most likely to become "school drop-outs" (15). It should be noted, however, that none of the above studies have been able to characterize the mediating variables associated with reduced academic performance which we have described in detail. These have important policy implications, suggesting that greater attention be given to early malnutrition as a hidden cause of learning failure (2).

We have demonstrated in this study that early malnutrition (with its accompanying conditions during infancy) and not socioeconomic conditions at the time of the study, is the major contributor to poor academic performance in school-aged children. Data from other studies examining this relationship are contradictory. Winick and his colleagues $(8,17)$ have provided strong evidence that among Korean children adopted into American families, some deficits due to early malnutrition can persist even when socioeconomic conditions are greatly improved; however, Richardson et al. (14) have reported that current socioeconomic conditions could not be separated from the effects of early malnutrition on school performance in his population of Jamaican school boys. This latter finding may be true under conditions in which there are extremes of economic status, but is not apparent in the relatively homogeneous Barbadian population. This does not exclude an effect of other features of the home environment such as the parent-child relationship, or level of parental education, or other factors linked with the original episode of malnutrition which in many cases was associated with poverty and substandard living conditions.

Finally, it is important to point out that at the time of study, the children with histories of malnutrition have the same weight/ height index as their comparisons (6), supporting the conclusion that the children are currently well-nourished. In view of the observations that iron deficiency may affect mental development (11), it should be pointed out that a recent follow-up study of our population in Barbados (J. Galler, personal observation) 


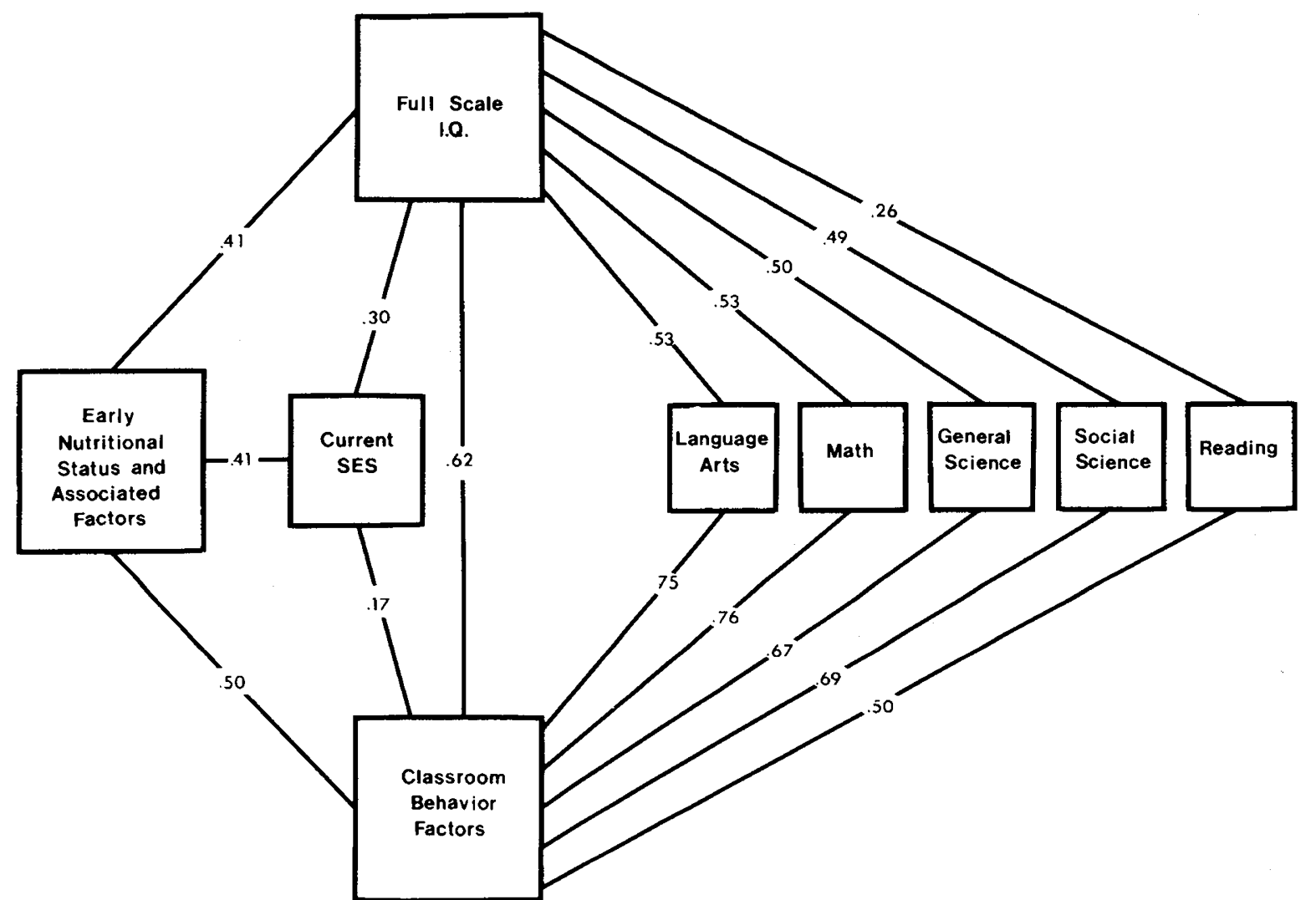

Fig. 1. A multifactorial model of the relationship between malnutrition and school performance. The correlation between current socioeconomic condition and classroom behaviors was calculated as the mean

failed to detect a significant difference in the frequency of irondeficiency anemia in index and control children.

\section{REFERENCES AND NOTES}

1. Anastasi, A. and Foley, J.: Differential Psychology; Individual and Group Differences in Behavior. (MacMillan Co, New York, 1949).

2. Birch, H. G. and Gussow, J. D.: Disadvantaged Children, Health, Nutrition, and School Failure. (Grune and Stratton, Inc., New York, 1970).

3. Evans, D. E., Moodie, A. D., and Hansen, J. D. L.: Kwashiorkor and intellectual development. S. Afr. Med. J. 45: 1413 (1971).

4. Galler, J. R., Ramsey, F. Solimano, G., Lowell, W. E, and Mason, E: The influence of early malnutrition on subsequent behavioral development. I) Degree of impairment in intellectual performance. J. Am. Acad. Child Psych., 22: 8 (1983a).

5. Galler, J. R., Ramsey, F., Solimano, G., and Lowell, W. E.: The influence of early malnutrition on subsequent behavioral development. II) Classroom behavior. J. Am. Acad. Child Psych., 22: 16 (1983b).

6. Galler, J. R., Ramsey, F., Solimano, G., and Propert, K.: Sex differences in the growth of Barbadian school children with early malnutrition. Nutr. Rep. Int. 27: 502 (1983c).

7. Gomez, F., Galvan, R. R., Cravioto, J., and Frenk, S.: Malnutrition in infancy and childhood with special reference to Kwashiorkor. In: S. Levine: Advances in Pediatrics. Vol. 7, p. 131 (Yearbook, New York, NY, 1955).

8. Lien, N. M., Meyer, K., and Winick, M.: Early malnutrition and "late" adoption: a study of their effects on the development of Korean orphans adopted into American families. Am. J. Clin. Nutr., 30: 1734 (1977).

9. Nie, N. H., Hull, C. H., Jenkins, J. G., Steinbrenner, K., and Bent, D. H.: Statistical Package for the Social Sciences. (McGraw Hill, Inc. New York: 1975). canonical root and was not significant. All other correlations were calculated using multiple regression techniques and were significant at the 0.01 level or better.
10. Pereira, S. M., Sundararaj, R., and Begum, A.: Physical growth and neurointegrative performance of survivors of protein-energy malnutrition. Brit. J. Nutr., 42: 165 (1979).

11. Pollitt, E. and Leibel, R.: Iron deficiency and behavior. J. Pediatr., 88: 372 (1976).

12. Richardson, S. A.: The background histories of schoolchildren severely malnourished in infancy. In: I. Schulman: Advances in Pediatrics. Vol. 21 (Year Book Medical Publishers, Chicago, 1974).

13. Richardson, S. A.: The long-range consequences of malnutrition in infancy: a study of children in Jamaica, West Indies. In: B. Wharton: Topics in Pediatrics 2: Nutrition in Childhood. (Pitman Medical Publishers, London 1980).

14. Richardson, S. A., Birch, H. G., and Hertzig, M. E.: School performance of children who were severely malnourished in infancy. Am. J. Ment. Def., 77: 623 (1973).

15. Rutter, M. and Madge, N.: Cycles of Disadvantage: A Review of Research. (Heinemann, London, 1976).

16. Singh, M. D. and Anand, N. K.: Scholastic performance in relation to protein calorie malnutrition. Indian J. Psychometry and Educ., 7: 5 (1976).

17. Winick, M., Meyer, K. K., and Harris, R. C.: Malnutrition and environmental enrichment by early adoption. Science, 190: 1173 (1975).

18. Dr. Ramsey is the Director of the National Nutrition Centre, Barbados, West Indies.

19. Dr. Solimano is Professor at the Institute of Human Nutrition and Center for Population and Family Health, Columbia University, New York.

20. Requests for reprints should be addressed to: Dr. Galler, Professor and Associate Chairperson, Department of Child Psychiatry, Boston University School of Medicine, 85 East Newton Street, Boston, MA. 02118, USA

21. This research was supported by grants from the Ford Foundation and the Thrasher Foundation.

22. Received for publication January $27,1983$.

23. Accepted for publication July 8, 1983. 